\title{
Research of Logistics Management of E-Commerce Retail
}

\author{
Cen Xia, Zhang Yu, Guo Hua* \\ Institute of Regional Economics and Finance, School of Economics \\ Sichuan Agricultural University \\ No.211 Huimin Road, Wenjiang District, Chengdu, Sichuan, China, 611130
}

\begin{abstract}
Recent years, electric retail platform is also mushroomed as the rapid development of its growth rate far beyond people's imagination. But China is a developing country, logistics development started late and its level was low, do not yet have a sound logistics system, which also has many problems. Therefore, to improve the shortcomings of the existence of China's e-commerce industry in such a complex and diverse industry comes to the forefront of the key step. Based on a large number of existing literatures, this paper using literature review, case analysis and other methods focuses on the current situation of logistics management under the current e-commerce environment, taking Taobao as an example to study the problems existing in the logistics management of the retail platform, and put forward the corresponding improvement to promote the further development of the future.
\end{abstract}

Keywords-E-commerce; Retail Business; Logistics Management; Taobao

\section{INTRODUCTION}

\section{A. Purpose and Significance of the Study}

In the information age, the impact of the Internet in our lives is growing, people gradually tend to use the Internet to solve the needs of daily life, and the number of online transactions is increasing. However, most products and services also need to be completed by manual distribution of logistics channels to complete the transaction. Therefore, the modern economic environment of the electricity supplier logistics is to use advanced information technology to maximize profits and minimize costs, so that modern logistics distribution can achieve the best level. So e-commerce can grow and develop with its corresponding logistics system

Among the traditional enterprise departments are independent of others, without mutual influence, just carry out their duties, so there are also factors, such as time-lag caused by inefficient business transactions, information which is not completely symmetrical, resulting in low anti risk ability and high transaction costs. On the contrary, although the modern logistics enterprise under the electronic commerce environment realize information symmetry, the transactions on the Internet still need logistics enterprises which can provide professional logistics service to complete the last-mile distribution. In a word, it is evident that the influence of modern logistics in ecommerce activities and the relationships between e-commerce

*Corresponding author. Tel.:+86 028-8629096

E-mail: huaguohua@sina.com,44528960@qq.com. and logistics is also gradually close. In order to promote the development of e-commerce, the electricity supplier logistics have emerged.

With the increase of online shopping, competition among ecommerce sites is increasingly fierce, the problems of Taobao are highlighting, and the profit margins are gradually reduced, thus taking Taobao as an example, to find out its risk or problems in the logistics in the current environment, help to improve its market competition, and gradually improve the logistics system

\section{B. Research Status at Home and Abroad}

Compared to developed countries, China's logistics development started late, and level is relatively backward. Since the development of logistics in China, Wang Zhitai (1995) has introduced the development, concept, storage, transportation and installation of logistics in detail, which is a comprehensive and systematic study of logistics in the early stage of our country [1]. As the time goes by, some scholars began to study e-commerce logistics, but the views are still not uniform. Xu Minhui (2004) understood it as a logistics industry which is a new industry of e-commerce [2]. Xu Dan (2005) interpreted it as the e-commerce of logistics enterprises, namely, the use of e-commerce technology to transform traditional logistics [3]. In our country, logistics is the bottleneck of the development of e-commerce. This topic has been concerned and discussed by many scholars, and logistics bottleneck theory has always been one of the focuses of attention. Zhu Yiqiu (2006) named inventory, warehousing and transportation of three core activities after yuan logistics activities, and saw supplement, production and sales ,supply chain and international logistics system as these activities, they are the basis of integrated logistics management [4]. Zhang Duo (2009) believed that the final Western e-commerce was to solve the information flow, business flow, capital flow on the handling of complicated delay of the logistics process, improving the current logistics speed, and he pointed out that logistics was the main part of e-commerce, online transactions can solve the information flow, business flow, capital flow, but could not solve the problem of logistics. E-commerce still needed to solve the physical distribution, and logistics is the guarantee of the realization of e-commerce [5].

Foreign logistics developed earlier, R.Borsodid firstly defined Logistics in 1927 [6]. In 1935, the American 
Marketing Association defined "Physical Distribution" as the material information and services contained in the sales and the activities, and it was associated with the flow from production place to consumption place [7]. During the Second World War, the United States in the wartime supply, firstly used "Logistics Management "in the term of ammunition transport, supply management. Later, this method was introduced to the business sector, which was called business logistics [8]. Later, Professor Nishizawa Shu called the improved logistics system "the third profit source" yet to be tapped [9]. Many foreign logistics experts and e-commerce experts have done a lot of research on e-commerce logistics. Roger Hallowell believed that in the era of information economy, e-commerce has brought convenience and fast to our life [10]. In 1999, the United States suffered Internet economic bubble, and the role of e-commerce logistics was becoming increasingly important. Haul Lee, Seungin Whang pointed out that the logistics distribution could realize the end of the distribution of goods online trading, which was the last link to complete the entire electronic commerce activity, and it showed that the third party logistics was the result of social division of labor and logistics industry. So, the third party logistics distribution has become the best mode of ecommerce logistics distribution, it could bring great economic benefits and social benefits to the electronic commerce [11].

\section{The Main Contents of the Study}

This paper is based on the summary of the existing literature, and the method of case analysis is used to study the current situation and existing problems of the retail logistics. The main contents are as follows:

The first chapter is to introduce the concept of logistics management in e-commerce environment, and the relationship between e-commerce and logistics management.

The second chapter is to focus on the characteristics of retail logistics, logistics distribution model and the application of information technology.

The third chapter is to take Taobao as an example to illustrate the problems existing in Taobao logistics and give suggestions.

The fourth chapter is to summarize the conclusions of this paper, as well as the future development trend of retail logistics.

\section{E-COMMERCE LOGISTICS CONCEPTS}

\section{A. Meaning of E-Commerce Logistics}

E-commerce logistics refers to under the e-commerce environment, use computer technology, Internet technology, ecommerce technology, as well as information technology to finish logistics activities [12].

E-commerce logistics informatization is reflected in the whole logistics activities, whether in the transport of goods, warehousing and preprocess, or the process of transaction or service. Through the realization of the logistics informatization, we can reform and perfect the existing logistics system, and gradually form a modern logistics system with high efficiency, low cost. E-commerce logistics makes modern logistics become informatization, automation and flexibility, and gradually realize the win-win situation of modern logistics and e-commerce, which is its essential characteristic.

\section{B. Relationship between E-Commerce and Logistics}

\section{1) Role of the development of e-commerce in logistics}

E-commerce can change people's traditional concept. The traditional logistics models separate and do not integrate with each other. Each process in traditional logistics is undertaken by different logistics main bodies, which lack of unified and systematic Management Information System, so the traditional logistics model usually has time-lag, low efficiency and high cost, however, the e-commerce can change these shortcomings, providing a virtual space for the modern operation logistics, so logistics can make a lot of processes on the Internet, simplifying the processes between the time interval.

E-commerce can change the logistics' running mode and provide transparent information. Informatization is the remarkable characteristic of e-commerce logistics, which makes logistics information can be queried in the network, achieves a real sense of order tracking, enabling customers to keep abreast of logistics information.

E-commerce can change the management pattern of logistics enterprises. The environment of e-commerce makes the logistics enterprises to change from decentralized management mode before to present mode considering the whole social logistics system, and makes the logistics enterprises more standardized, systematic and standardized. On the other hand, because of the integration of logistics enterprise, management patterns have been change, and modern logistics enterprises have begun to attach importance to value-added services in the environment of e-commerce, it is no longer engaged in the commodity storage or transfer, more is to provide good services to improve market competitiveness.

E-commerce can promote the improvement of logistics infrastructure and improve the management level of logistics enterprises. Modern logistics in e-commerce environment are operating through the network system. In order to achieve high efficiency and low cost, it is necessary to improve the infrastructure of logistics system, so factors such as good traffic conditions, cargo electronic inquiry system are indispensable. In addition, logistics enterprises have been further developed, and also should improve the management level of enterprises. Scientific management methods and means are conducive to the realization of efficient operation of logistics enterprises, achieving the global logistics network and realizing the healthy development of e-commerce industry [13].

\section{2) Logistics impact on e-commerce}

Huang Fuhua (2003) believed that the e-logistics should be an important part of e-commerce, e-commerce lacking of modern logistics processes is incomplete [14]. Tang Yongbo (2010) said that modern logistics served business flow, running modes of modern logistics is helpful to ensure the orderly and efficient conduct of electronic commerce [15].

E-commerce is composed of four parts, namely business flow, information flow, capital flow and logistics. Among them, the first three can be completed on the network, but logistics cannot use separately Internet to deliver goods home. But apart 
from some virtual goods, most of goods and services also need to use physical logistics mode for distribution, so the logistics plays an important role in the development of e-commerce, and is the basic elements of e-commerce. At present, most of trade is finished on the online transactions as the main way in China, and then the logistics enterprises deliver goods to customers. However, in the term of the current situation of our country, logistics system is not perfect enough, and it does not have the advantage of the global network. As a result, the delivery time may be too long and so on, which will affect the turnover of ecommerce. On the other hand, due to the high cost of logistics, when engaging in online transactions, the sellers not only need to collect commodity cost, also charge an extra fee of logistics distribution, which will affect the turnover, so e-commerce is largely dependent on the logistics system.

A healthy logistics system can promote the development of e-commerce. E-commerce can provide efficient trading so as to reduce the transaction cost and inventory cost, but in order to ensure the smooth conduct of trade, production and delivery on time are the first step, and a healthy logistics system can guarantee the base. In addition, a good logistics system can promote the development of e-commerce through enhancing customer satisfaction and loyalty. Because modern logistics system can real-time query order details, so that customers can keep track of orders, improving the transparency of the transaction.

\section{E-COMMERCE RETAIL LOGISTICS SYSTEM}

\section{A. Characteristics of E-Commerce Retail Logistics}

What retail e-commerce different from physical retailing is that in the form of e-commerce retail, commodity is presented through a virtual image display mode, and the types of goods are broad and diverse, but consumers do not directly touch products. Customers only through the purchase details on an offer page or evaluation of buyers to understand the quality of the goods and materials, and goods must rely on logistics enterprises being distributed to consumers, after consumers' confirmation, the transaction is completed. However, in the physical retailing, goods in the form of visual presentation to the consumers can be directly touched, and payment is regarded as the final step of the transaction.

\section{1) E-commerce retail logistics system is more simplified}

E-commerce retail display goods and related information to consumers receiving orders online on the Internet, and then physical logistics enterprises deliver the goods ordered by consumers, the retail logistics distribution system is shown in Figure 1 [16], and the system omits the intermediate links from the distribution centers to the retail stores in the traditional retail distribution process.

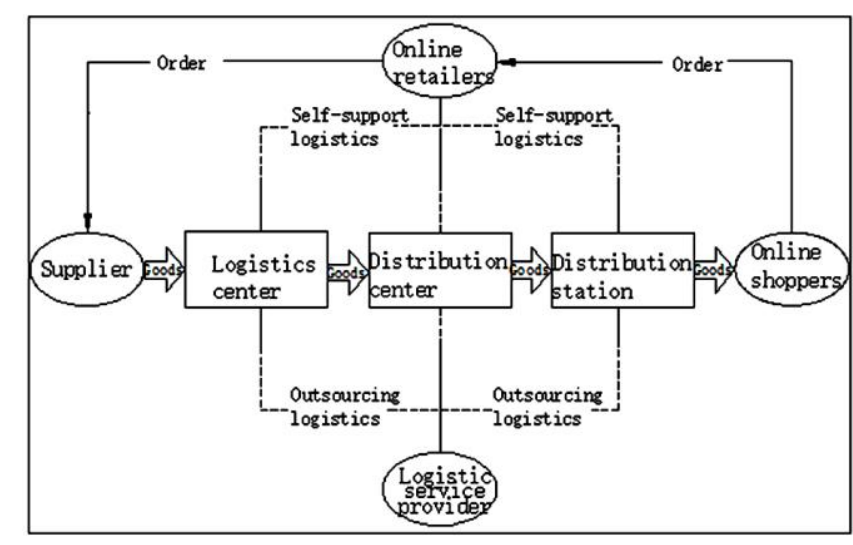

Fig. 1. Retail Logistics Distribution System

From the figure 1, customers have become a part of the retail e-commerce logistics system. So e-commerce logistics system will be different from the characteristics of physical retail logistics system. For example, the number of orders is big, but the single order number is small, with the characteristics of multi variety and small batch, high frequency [17].

2) Service scope of e-commerce retail logistics is broad

As a result of modern logistics under the influence of ecommerce, it is not restricted to the scope of services between regions. And the current service scope of e-commerce retail logistics not only ranges between the city and the city, and even provides provincial cross-border services, expanding the scope of services to the whole nation and even the whole world.

3) Service items of e-commerce retail logistics is diverse

Online retailing simplifies logistics distribution system, providing great convenience for online shoppers. E-commerce retail logistics maintains the traditional e-commerce retail logistics service items, and meanwhile, begins to focus on value-added services, such as agency fund, order tracking, home delivery service, exchange items and so on. These valueadded services provide a guarantee to e-commerce retail logistics, and enhance customer satisfaction, further promoting the development of the e-commerce retail industry.

4) E-commerce retail logistics system is time-efficient

In transactions, delivery speed and distribution speed are one of the important factors affecting customer satisfaction, so in order to improve the transaction volumes and customer satisfaction, retail e-commerce logistics system must have timeliness. At present, many of the retail e-commerce logistics enterprises have the corresponding logistics services, for example, enterprises propose that orders before $4 \mathrm{pm}$ can be shipped the same day, orders after $4 \mathrm{pm}$ just can be shipped the next day before $11 \mathrm{am}$, which improves the efficiency of logistics distribution. 


\section{B. Operating Mode of E-Commerce Retail Logistics System}

In order to accelerate the development of e-commerce retail industry in the field of logistics enterprises in China, enterprises are based on successful experience and lessons, and according to China's current economic situation, the current operating modes are as follows:

\section{1) Self-support logistics}

Self-support logistics means that all processes of logistics do not rely on outsourcing, they are formed or purchased by the enterprise itself, and then the enterprise organizes and manages the whole logistics system for the logistics services. Logistics enterprises using this kind of mode can control all parts of logistics to shorten flow-time in the processes of logistics distribution, achieving high-efficient management. Moreover, zero inventory targets may be achieved under this kind of mode, and it can provide personalized logistics services. But there are also shortcomings. The enterprises adopting the self-support logistics mode usually have higher cost, greater risk, and may cause the failure of capital turnover. What's worse, the logistics distribution is usually short board of the enterprise, logistics enterprises using this mode need to spend more time, energy and financial resources to manage the logistics sector, which make logistics have a low level of specialization, and makes enterprises lose the core business competitiveness [18].

\section{2) Logistics integration}

Integrated Logistics is the integration and the systemization of the supply chain from manufacturing company, logistics enterprises, and sales company to customer [19].The pattern is suitable for enterprises whose management system is relatively mature. The development of logistics integration is divided into three parts: the integration of logistics itself, the integration of micro logistics and the integration of macro logistics [20].In fact, the integration of logistics is the organic combination professionals with equipment. Logistics professionals achieve best possible optimizations through using the logistics infrastructure and equipment to make use of the professional logistics process, which is not only conducive to optimize the allocation of social resources, but also can promote the healthy development of social economy.

\section{3) The third party logistics}

The third party logistics refers to the operation mode of logistics service provided by the third party enterprises besides the supply side and the demand side of the logistics service. A significant feature of the mode is that the relationship between logistics service provider and the demand of logistics is established through a contract, and the former provides the necessary logistics services for the latter. Therefore, the third party logistics enterprises are quite professional, and provide customized and professional logistics services. The advantages of logistics service demand-side are also obvious, it can have enough energy to focus on the development of core business, and obtain profits in their respective fields with higher efficiency. But there also exist some problems, typically, enterprises cannot directly supervise logistics function; cannot ensure that suppliers accurately and timely deliver goods and cannot ensure the quality of service to make customer satisficed; besides, the enterprise must rely on the contract between the logistics enterprises, resulting in their lack of development of logistics function.

\section{4) Logistics alliance}

Logistics alliance is a kind of strategic alliance, which is composed of two or more enterprises on the basis of logistics cooperation, in order to achieve their own strategic goals of logistics. The main feature is the common establishment use of logistics system to achieve common profits. The mode is helpful to reduce the risk of enterprises, and the risk can also be shared by the alliance enterprise. In addition, each enterprise can provide their own superior resources for alliances to reduce the cost. Finally, it can improve the logistics professionalism, and the alliance between enterprises is a long-term and stable cooperation for the pursuit of common profit.

\section{5) Fourth party logistics}

Fourth party logistics is a supply chain integrator, not provides the actual logistics service, but the integration of excellent supply and demand of resources logistics and third party logistics, providing operational and valuable supply chain solutions to meet the customer needs of logistics operation and realize high efficiency and low cost. The mode has the advantages of low operating cost and strong resource integration ability, and the enterprises invest less capital. The main value of the enterprises is to provide supply chain solutions, so they do not have their own logistics system, thus causing low credibility. In addition, the relationship between the fourth party logistics and third party logistics are instable, the third party logistics can give up the original partners, and make alliances with others. If so, cooperation will be transformed into the competition, which has adverse effects on the fourth party logistics.

\section{Application of E-Commerce Retail Logistics Information Technology}

Logistics information technology occupies an important role in the modern e-commerce logistics. With the use of information technology, it can ensure the advantages of the ecommerce retail logistics and the smooth operation of the operating mode. E-commerce retail logistics is driven by ecommerce retailing, and the smooth implementation of the ecommerce retail logistics must be guaranteed through the application of information technology. At present, information technology that e-commerce retail logistics use in China mainly as follows:

\section{1) Logistics information network system}

Logistics information network system includes at two aspects, one is the resource information management system for enterprise internal logistics operation to collect the data. And the system performs analytics to realize the real-time supervision and achieve the optimal allocation of all logistics resources. The other one is the management system for connection between the customer and the enterprise. The system is used to collect customer required logistics demand and deliver it to the logistics enterprises timely in a standardized form, to provide high quality service for customers and achieve effective docking of information resources. 


\section{2) Bar code recognition technique}

The application of bar code recognition technology in modern logistics is to identify, input and manage the commodity information conveniently and quickly. Bar code is just like a commodity identification card which is consisted of a number of black bars and blank figures according to the coding rules. It is used to indicate the basic information of the commodity name, date of manufacture, place of manufacture and manufacturer. Bar code technology has the advantages of low cost, high efficiency, large amount of input information and accuracy.

\section{3) Radio frequency identification}

Radio frequency identification (RFID) is a non-contact automatic identification technology, which can be used to identify, read and write items in circulation. The main signature is that scanning technology has quick recognition speed, and the technology has high security and strong penetration characteristics. It is mainly used for querying goods in transit, and usually docking with the logistics management information system to improve work efficiency.

\section{4) Geographic information system}

Geographic information system (GIS) refers to a computer system that has maps and geographic information, and sometimes analyses of geographic data. The technology is regional, spatial and dynamic. GIS is used for logistics analysis in logistics activities to determine the shortest route of logistics distribution, and locate goods.

\section{5) Global positioning system}

Global positioning system (GPS) is a kind of information technology that uses navigation satellites to measure time and distance. It has the characteristics of global coverage rate as high as $98 \%$, high precision, timing positioning, high speed and high efficiency. In logistics activities, it is usually used to track and transport important goods. It can solve the problem of delivering goods, and realize real-time tracking and rapid delivery.

\section{TAKE TAOBAO AS AN EXAMPLE TO ANALYZE THE E-COMMERCE RETAIL LOGISTICS}

Taobao is the first advanced personal e-trade platform, financed by the best B2B website Ali Baba in 2003. It is the biggest web retails a shopping zone in the Asia Pacific region, and is a popular online shopping retail platform in China. The number of registered users is nearly 500 million, more than 60 million visitors a day, and meanwhile, the number of goods online is more than 800 million every day, the average of sales is 48 thousand per minute. In the $\mathrm{C} 2 \mathrm{C}$ market, Taobao accounts for $95.1 \%$ market share. Taobao grows quickly in the mobile terminal, Taobao and T-mall account for $85.1 \%$ of the market share in 2016. Up to now, Taobao has created a large number of direct employment opportunities. With the expansion of the scale and users are constantly increasing, Taobao changes from a single $\mathrm{C} 2 \mathrm{C}$ network platform to comprehensive retail district including $\mathrm{C} 2 \mathrm{C}$, group purchase, distribution, sale and other ecommerce modes. At present, it has become a world-famous ecommerce trading platform. The establishment of Taobao has provided a real, transparent and open trading platform for the entire online shopping market environment and it has become a major breakthrough in changing the shopping patterns of consumers, and formed a new business transaction culture [21].

\section{A. Analysis of the Current Situation of Taobao Logistics}

Main business of Taobao is to provide online shopping transactions, in order to provide online shoppers convenient and efficient service, logistics system is necessary. At present, the cooperation mechanism of supply chain of Taobao is that Taobao and large logistics companies form partnerships through signing contract. In the contract, trading platform is provided by Taobao, and buyers complete the order transaction on this platform, orders are processed and accepted by logistics companies, completing the commodity the distribution. Among these logistics enterprises, Taobao reached a cooperative relationship with the logistics enterprises SF EXPRESS, Shentong Express, ZTO Express, YTO Express, rhyme Express and so on [22]. In 2010, Taobao announced the formal launch of the large logistics program, which mainly includes three major aspects: Taobao logistics platform, logistics partner system and logistics service standard system. The implementation of the plan changes the traditional business model, and achieves effective resources integration, which makes Taobao, sellers, and logistics enterprises as a whole establishing good links. The plan not only enhances the specialization degree of logistics services, but also reduces the business logistics cost improving the efficiency of Taobao.

\section{B. Recommended Logistics of Taobao}

Taobao do not have exclusive logistics system and adopts the form of recommended logistics. Taobao signs an agreement with the logistics companies, and the agreement requires that users can select logistics enjoying related services and support, moreover, related services prices, contents, forms and corresponding compensation policy and regulatory policies are presented in the contract. The main form of recommended logistics of Taobao is that Taobao and logistics companies have reached a cooperation agreement, and Taobao collects and reports relevant data of logistics companies, then information will be released to consumers. Consumers purchase goods through online to get delivery logistics service and recommended logistics enterprises receive orders online to provide the corresponding service.

In the agreement, Taobao has the authority to regulate and supervise the logistics enterprises providing payment policy for online buyers, when the legitimate rights of online consumers are not protected, buyers can apply for Taobao intervening in the case and urging logistics enterprises to timely correct misconducts. In addition, Taobao also provides logistics consulting service, which is convenient for consumers to consult the relevant logistics problems, customers do not need to contact the logistics enterprises by themselves achieving completely online transactions. Taobao provides service of order tracking facilitating the customers timely to query shipment of goods. Taobao has a special function--calculation of the logistics price, when order is complete, according to the address of buyers and sellers, Taobao automatically calculates the required logistics cost for the customers choosing satisficing logistics enterprises. 
Order status of Taobao recommended logistics are mainly divided into the following five types: orders of waiting for delivery, orders of waiting for the logistics company to confirm, orders of waiting for the logistics company soliciting, orders of waiting for the customers to sign, orders of the customers has signed [23]. These five types of order status mainly make the buyers and sellers manage their orders effectively, which improve the work efficiency and facilitate the management of the logistics operation.

\section{The Existing Problems of Taobao Logistics}

1) The lack of appropriate return mechanism for buyers

As online shopping cannot directly touch the goods, the objects may be in error with the picture, so some unsatisfactory goods need to be returned. According to the current situation of Taobao, when in return, logistics company which sign a cooperation agreement with the Taobao is not involved in this process, so return mechanism for buyers is quite complex. Buyers need to contact the sellers of Taobao to apply for returning or exchanging goods, and provide evidences that the object does not meet the requirements. After the seller agrees with the application, customers contact the logistics enterprises to return goods to the seller. This process is not only timeconsuming, but also for buyers who do not buy freight insurance is undoubtedly increased the additional cost of logistics. In addition, because the logistics company is not involved in this process, its responsibility for problems caused by logistics cannot be held, which will greatly blow buyers' enthusiasm of choosing to continue the purchase.

\section{2) Inconvenient delivery and high logistics distribution} costs

Although Taobao launched a centralized storage for sellers to pack the goods in the designated warehouse to manage, the sellers are geographically fragmented. The problem is that distance between the position of sellers and warehouse is far, so it causes inconvenience to the delivery, and increases transportation cost. Under the influence of e-commerce, warehouse management uses the information system to query the number of stocks, but it cannot carry out the quality of goods management and check whether book amount is consistent with actual quantity. In addition, sellers and buyers are decentralized, coupled with the inconvenience of location, so it will increase the number of dispersed delivery and increase physical distribution cost.

\section{3) Poor quality of logistics distribution service}

Among logistics companies signing contract with Taobao, the quality of service is a little patchy, so it makes customers dissatisfied. From the evaluation of the buyers, the logistics distribution is not very good, damaged and lost goods are common. A number of consumers reflect that service attitude of logistics personnel is poor, their lack of professional quality and occupation moral cause a lot of inconvenience to consumers, so consumers blame complaints about logistics services on the sellers of Taobao affecting the credibility of the sellers. There are regional coverage of logistics distribution is incomplete, cargoes only can be delivered to the designated hubs, and customers come to pick up by themselves, which to a certain extent affects the consumer satisfaction of online shopping and affects the purchase of enthusiasm.

\section{Solutions}

\section{1) Establishment of retail buyers return service platform}

Retail return and exchange service platform refers to the establishment of a unified Taobao service platform to deal with the need to return goods of retail buyers. When in the return, in order to avoid contacting logistics companies to send back the goods, buyers only need to fill in the return application. After unified background processing accepted by Taobao, logistics company retake goods and return to the sellers. The humanized setting will provide convenience to customers and increase customer favor of Taobao, which is helpful to further development and expansion of Taobao.

\section{2) Establishment of Taobao regional warehouse}

To avoid too far distance between the position of sellers and the warehouses, Taobao can build large-scale and decentralized regional warehouse for sellers to store goods within a certain distance, which is convenient to manage at any time, and reduce the costs of cargo transporting from the warehouse to the delivery point, further promoting the Taobao large material flow plan [24].

\section{3) Establishment of credit evaluation system of logistics} service

Stores evaluation of Taobao mainly contains three parts: goods description, business services, and logistics services. After the completion of the transaction, buyers will make the corresponding evaluation, but it mainly focuses on the overall evaluation, there is little evaluation separately for the logistics. To a certain extent, the evaluation has great influence on the credibility of the sellers but not for larger logistics enterprises, so establishment of credit evaluation system of logistics service to measure credit rating is necessary, as for the lower level enterprises, Taobao can choose to cancel contract or require the rectification, and then select some good credit enterprise cooperation, which is helpful to improve the current situation of poor logistics service.

\section{DEVELOPING TRENDS OF E-COMMERCE RETAIL LOGISTICS}

\section{A. Information Technology of E-Commerce Logistics is Gradually Improved}

Informatization is a notable feature of modern logistics, and modern e-commerce cannot be separated from informatization management. Although the informatization level of ecommerce retail logistics in China is relatively low, in the future, information technology will be greatly improved. Nowadays, the scale of logistic network is increasingly large and logistic information is throughout the whole logistic activities, so using information to deal with logistic activities is essential requirement. Modern logistics enterprises can use information technology to carry out centralized processing and control of logistic information, improving the efficiency of solving all kinds of problems in the development of logistics enterprises. 


\section{B. Development of E-commerce Logistics is specialized}

In recent years, the online consumption in China showed a gradually increasing trend. Although the e-commerce retail logistics can still meet the demand in clothing, cosmetics and other public daily necessities, from the current situation, ecommerce retail logistics in fresh products such customized service has great room to grow. The personalized consumer demands stimulate pursuit of timeliness and quality for ecommerce retail logistics, therefore, the development of ecommerce logistics must be gradually specialized. The refinement of social division of labor and the individualization of demand require the division of e-commerce retail logistics to be refined so that the efficiency can be improved.

\section{Quality and Innovation Capability of E-Commerce Logistics Services will be Greatly Improved}

Logistics enterprises belong to the service enterprises, so the quality of service is the first. Consumption structure and the change of the times require e-commerce logistics to further improve the quality of service, in order to promote the healthy development of logistics enterprises, help enterprises stand out from the competitive environment, with establishing the longterm friendly and cooperative relations with customers. What's more, with the popularity of online shopping, consumer demand will be more diversified, e-commerce logistics must improve innovation ability to meet customer needs adapting to different market needs.

\section{Cost of E-Commerce Logistics is reduced}

Informatization is helpful to promote the information symmetry during transportation, so the logistics information can be more cooperative and integrated. To adjust expectations reduces duplicate and inefficient transportation, and reduces the extra transportation cost and transaction cost.

\section{CONCLUSION}

E-commerce logistics industry not only affects the development and growth of enterprises, but also its impact of the entire economic environment in the future is not to be underestimated, therefore its role is naturally self-evident. Although China's logistics started late, fortunately, the development momentum is enough; there is room for growth, so logistics is a promising industry. Based on the analysis of the case of Taobao, the paper mainly studies the e-commerce retail logistics management. There remain some problems, but e-commerce logistics industry has advantages. After reforming through taking improved measures, it can play a positive role.

Due to the large number of customers of Taobao, the logistics systems have also more attention. In order to promote the good development of Taobao, Taobao should cooperate with highly promising logistics enterprises, to strengthen the integration of e-commerce and logistics distribution system, and to promote Taobao integrated logistics plan. At present, although Taobao in terms of logistics distribution and logistics cooperation company management still has defects, but we believe that Taobao can provide better service and e-commerce logistics level in China will step into a higher level.

\section{REFERENCES}

[1] Wang Zhitai. Modern Logistics [M]. Beijing: China Materials Press, 2007, (03):19-20(In Chinese).

[2] Xu Minhui,Huang Hui. Discussion on the Development Strategy of Third Party Logistics in China [J]. Coal Mine Modernization,2004,(06):6 -7 (I n Chinese).

[3] Xu Dan. Research on logistics management model based on Ecommerce [D]. Heilongjiang: Harbin Institute of Technology,2005:8(I n Chinese).

[4] Zhu Yiqiu. Logistics management [M]. Shandong: Shandong people's publishing house, 2006,(02):5-8(I n Chinese).

[5] Zhang Duo. E-commerce and logistics [M].Beijing: Tsinghua University Press,2009 : 25(I n Chinese).

[6] R. Borsodid. Distribution Era [J]. Logistics Technology and Application, 2008, (01):2.

[7] Liu Jianhua. E-commerce and the Third Party Logistics Model [J]. Information Technology, 2002, (09):23-26(I n Chinese).

[8] Zhang Wenjie. Logistics management under E-commerce [M].Beijing: Tsinghua University Press,,2003 : 24(I n Chinese).

[9] Nishizawa Osamu. Distribution costs [M].Bejing: Tsinghua University Press, 2000:14(I n Chinese).

[10] Roger Hallowell. Service and Value in E-Commerce [J].Harvard Business Review, 2005:45.

[11] Haul Lee, Seungin Whang.Winning the Lastmile of the E-Commerce [J].McGraw-Hill Companies, Ins, 2002:32.

[12] Wei Xiujian.The Development of E-commerce Logistics [M].Chongqing Chongqing University Press,2008:38.

[13] Liu Lin,Jiang Ming,Yu Jian. Discussion on the Relationship between ECommerce and Logistics [J]. Logistics Technology, 2002, (01):23-26(I n Chinese).

[14] Huang Fuhua. Discussion on Coordinated Development of E-Commerce and Logistics in Hunan [J]. National Discussion, 2003, (02):27-28(I n Chinese).

[15] Tang Yongbo. Research on the Relationship between E-Commerce and Modern Logistics [J]. Journal of Hunan Institute of Industry and Technology, 2010, (10):50-52(I n Chinese).

[16] Cai Yunjiao,Wang Chuanlei,Zhu Yuwang. Characteristic Analysis and Operation Strategy of Network Retail Logistics System [J]. Logistics Technology, 2015, (11):23-25(I n Chinese).

[17] Li Yin. Analysis of E-Commerce Retail Logistics System [J]. Technology and Enterprise, 2012, (11):91(I n Chinese).

[18] Sang Xiaojuan. Analysis of E-Commerce Retail Logistics Distribution Mode -- Taking Logistics Distribution of Alibaba as an Example [J]. Journal of Jiangsu Institute of Economic and Trade Technology, 2013, (0 1):13-16+28(I n Chinese).

[19] Liang Shuhui,Rong Juling,Zhou Yongsheng. Research on the Current Situation and Countermeasures of E-Commerce Logistics [J]. Chinese Market,2015,(12):164-168(I n Chinese).

[20] Yao Yougang. Research on E-Commerce Logistics Model [J]. Management \& Technology of SME, 2010, (07):250(I n Chinese).

[21] Shi Xiaodan,Jia Hongyan,Sun Deyou. Customer Satisfaction Survey of Online Shopping Based on Taobao [J], 2013, (07):19-24(I n Chinese).

[22] Lan Zhaoqin, Wang Mingyu,Zhou Lin. Taobao Logistics Analysis [J]. ECommerce, 2014, (10):27-28(I n Chinese).

[23] Zhang Haixia,Li Zhongqin. Logistics Form of E-Commerce in China from Taobao Logistics [J]. China Business \& Trade, 2010, (16):118119(I n Chinese).

[24] Zhou Xizhao,Tang Zhujian. Study on the Countermeasures of Taobao logistics development [J]. Journal of Taiyuan Urban Vocational College, 2016, (01) (In Chinese). 